\title{
Structure and Properties of Melt-Spun Mg-Pd Binary Alloys
}

\author{
Shin-ichi Yamaura*, Hisamichi Kimura and Akihisa Inoue \\ Institute for Materials Research, Tohoku University, Sendai 980-8577, Japan
}

Amorphous alloys in the Mg-Pd binary system were formed in a composition range of 10 to 35 at\%Pd by melt-spinning technique. The crystallization temperature and tensile strength of the amorphous $\mathrm{Mg}_{100-x} \mathrm{Pd}_{x}(x=10,20$ and 30 at $\%)$ alloys are in the range from 417 to $535 \mathrm{~K}$ and 440 to $650 \mathrm{MPa}$, respectively. There is a tendency for the crystallization temperature and the tensile strength to increase with increasing Pd content. Vickers hardness also increased with increasing Pd content. Their compositional dependence is attributed to an increase in the number of $\mathrm{Mg}-\mathrm{Pd}$ atomic pairs with large negative mixing enthalpy. Crystallized structure of the $\mathrm{Mg}-\mathrm{Pd}$ amorphous alloys was also examined in correlation with equilibrium phases.

(Received June 10, 2003; Accepted July 29, 2003)

Keywords: amorphous, melt-spinning, magnesium-palladium (Mg-Pd) alloy

\section{Introduction}

Recently, Mg-based alloys have attracted increasing interest because of their useful engineering properties such as high strength with light weight ${ }^{1)}$ and high hydrogenstorage capacity. ${ }^{2)}$ It is well known that the structural modification to an amorphous phase significantly increases various properties as compared with crystalline alloys. ${ }^{3)}$ An amorphous phase has been formed in a number of $\mathrm{Mg}$-based alloy systems such as $\mathrm{Mg}-\mathrm{Cu}^{4)}$ and $\mathrm{Mg}-\mathrm{Ln}-\mathrm{TM}(\mathrm{Ln}=$ lanthanide metal). ${ }^{5)}$ Particularly, the Mg-Ln-TM alloys are important because they have a large supercooled liquid region before crystallization and high glass-forming ability. ${ }^{6}$ It has subsequently been reported that the plateau region in electrochemically measured P-C isotherm and high electrochemical discharge capacity are obtained in $\mathrm{Mg}-\mathrm{Ni}^{7,8)}$ and $\mathrm{Mg}-\mathrm{Ni}-\mathrm{Pd}^{9)}$ amorphous alloys. In addition to $\mathrm{Mg}-\mathrm{Ni}$ amorphous alloys, $\mathrm{Mg}-\mathrm{Pd}$-based amorphous alloys are also expected as a base alloy system to develop useful functional materials with high hydrogen absorption ability. However, there have been no data on the formation of an amorphous alloy in $\mathrm{Mg}-\mathrm{Pd}$ binary system. Furthermore, little has been reported about the formation of $\mathrm{Mg}$-based amorphous alloy with high $\mathrm{Mg}$ content above 85 at\% except the $\mathrm{Mg}-\mathrm{Ni}$ binary system. Therefore, this paper intends to present the composition range in which an amorphous phase is formed in $\mathrm{Mg}-$ Pd binary system by melt-spinning and intends to investigate the reason for the formation of the amorphous phase even at the Mg-rich compositions. The thermal stability and mechanical properties of the $\mathrm{Mg}-\mathrm{Pd}$ amorphous alloys were also studied in this work.

\section{Experimental Procedure}

$\mathrm{Mg}-\mathrm{Pd}$ binary alloy ingots were prepared by highfrequency induction melting the mixtures of pure $\mathrm{Mg}$ and Pd metals in an Ar atmosphere. Ribbons of about $20 \mu \mathrm{m}$ in thickness and about $1 \mathrm{~mm}$ in width were produced by a single-roller melt-spinning technique in an Ar atmosphere. The circumferential velocity of the wheel $\left(v_{\mathrm{c}}\right)$ was controlled

*Corresponding author, E-mail: yamaura@imr.tohoku.ac.jp as $40 \mathrm{~m} / \mathrm{s}$. The structure of the melt-spun ribbons was examined by X-ray diffractometry (XRD; Cu-K $\alpha, 35 \mathrm{kV}$, $15 \mathrm{~mA}$ ) and by Transmission Electron Microscopy (TEM). Crystallization temperature $\left(T_{\mathrm{x}}\right)$ was examined by differential scanning calorimetry (DSC) at a heating rate of $0.67 \mathrm{~K} /$ $\mathrm{s}$. Tensile fracture strength was measured at a strain rate of $8 \times 10^{-4} \mathrm{~s}^{-1}$ with an Instron-type testing machine. Hardness was also measured by a Vickers microhardness tester with a load of $10-25 \mathrm{~g}$.

\section{Results and Discussion}

Figure 1 shows XRD patterns of the melt-spun $\mathrm{Mg}_{100-x} \mathrm{Pd}_{x}$ $(x=2,4,6,8,10,20,30$ and 40 at\%) alloys. Distinct crystalline peaks of Mg phase are seen in the XRD patterns of the $\mathrm{Mg}_{100-x} \mathrm{Pd}_{x}(x=2,4,6$ and 8 at $\%)$ alloys. Intensity of the sharp peaks decreases with increasing Pd content from 2 to 8 at $\%$ and no crystalline peak is observed at 10 at $\%$ Pd. Only broad diffraction peaks are seen for the $\mathrm{Mg}_{100-x} \mathrm{Pd}_{x}(x=10$, 20 and 30 at\%) alloys, indicating the formation of an amorphous phase. Sharp crystalline peaks are also seen in the XRD pattern of the $\mathrm{Mg}_{60} \mathrm{Pd}_{40}$ alloy. The sharp peaks of the 40 at $\% \mathrm{Pd}$ alloy may come from $\mathrm{MgPd}$ phase according to the previous reports, ${ }^{10,11)}$ though there is no data in the ICDD cards on the XRD patterns of $\mathrm{Mg}_{4} \mathrm{Pd}, \mathrm{Mg}_{3} \mathrm{Pd}$ and $\mathrm{MgPd}$ alloys.

Figure 2 summarizes the composition range in which amorphous $\mathrm{Mg}-\mathrm{Pd}$ alloys are formed by melt-spinning, together with the $\mathrm{Mg}-\mathrm{Pd}$ binary phase diagram. ${ }^{12)}$ The amorphous phase is formed in a composition range of 10 to 35 at $\% \mathrm{Pd}$. According to the $\mathrm{Mg}-\mathrm{Pd}$ phase diagram, a eutectic point is located at $7.8 \mathrm{at} \% \mathrm{Pd}$. Therefore, it is understandable that the minimum $\mathrm{Pd}$ content at which the $\mathrm{Mg}-\mathrm{Pd}$ amorphous phase can be formed lies near the eutectic composition. The upper limitation of $\mathrm{Pd}$ content for the formation of the amorphous phase may be due to the increase in melting point.

Figure 3 shows bright-field TEM images of the melt-spun (a) $\mathrm{Mg}_{92} \mathrm{Pd}_{8}$ and (b) $\mathrm{Mg}_{90} \mathrm{Pd}_{10}$ alloys. No crystalline phase is seen in the melt-spun $\mathrm{Mg}_{90} \mathrm{Pd}_{10}$ alloy while fine crystalline particles are recognized in the $\mathrm{Mg}_{92} \mathrm{Pd}_{8}$ alloy. A halo-type diffraction ring pattern for the $\mathrm{Mg}_{90} \mathrm{Pd}_{10}$ alloy was also obtained while reflection spots were observed for the 

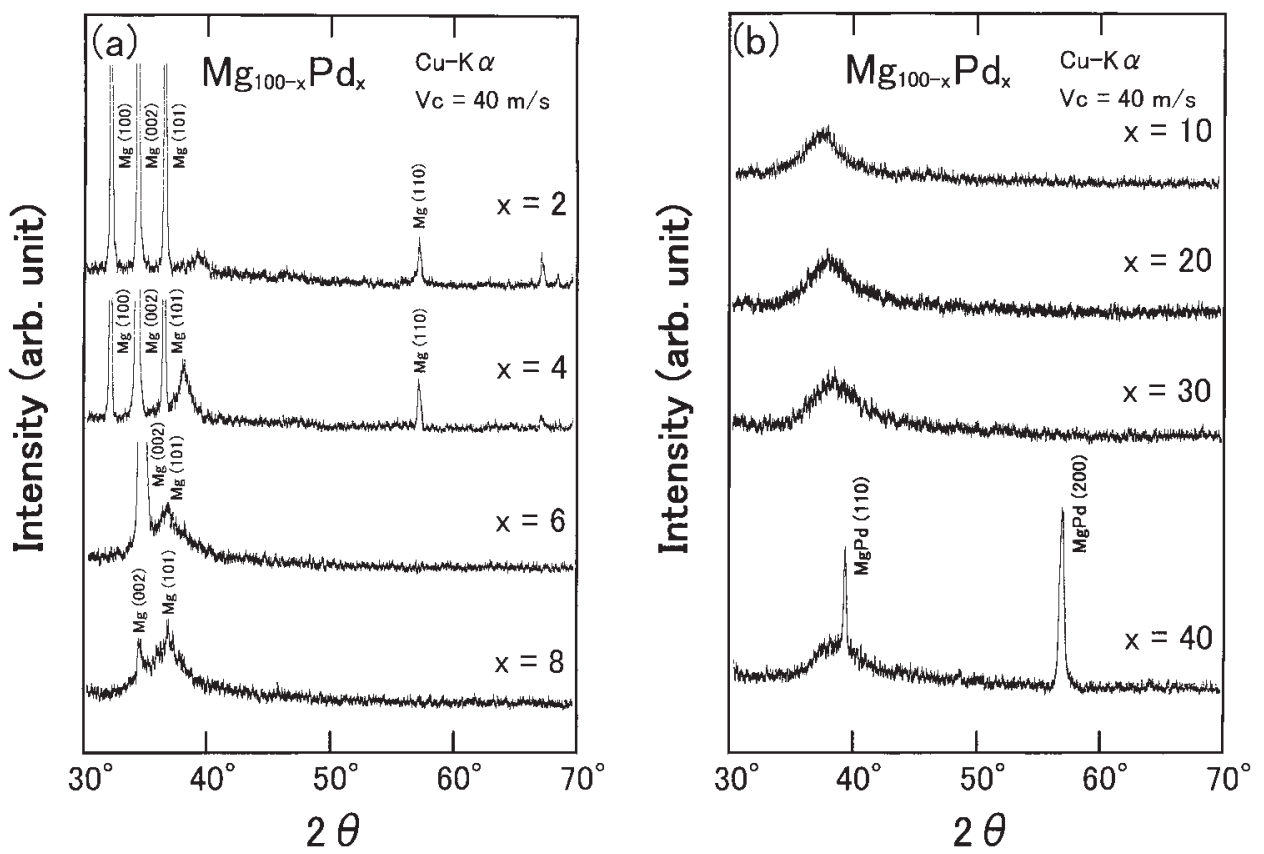

Fig. 1 XRD patterns of melt-spun $\operatorname{Mg}_{100-x} \operatorname{Pd}_{x}(x=2,4,6,8,10,20,30$ and 40 at $\%)$ alloys.

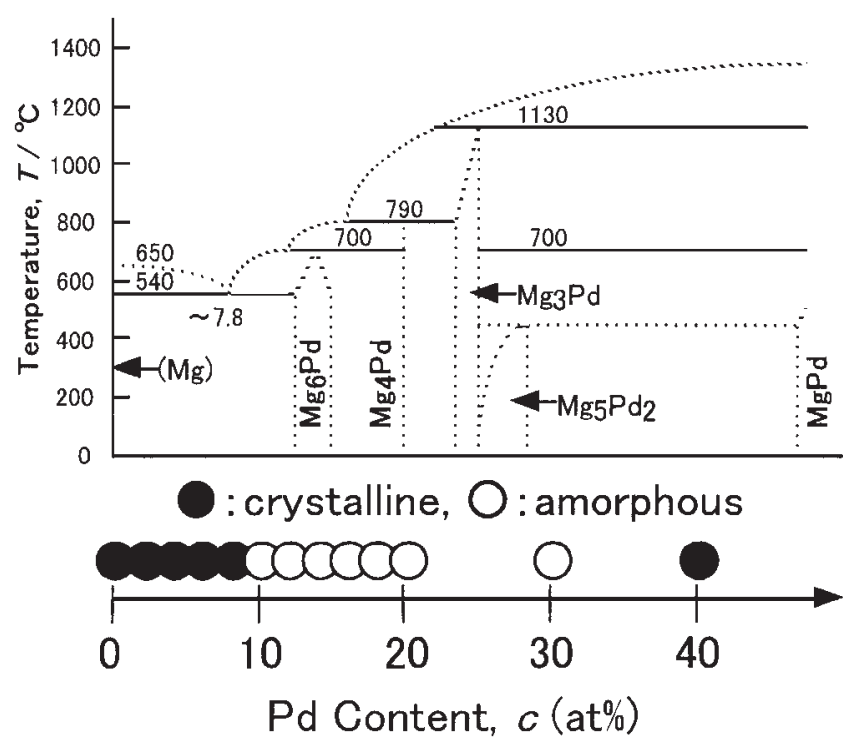

Fig. 2 Composition dependence of structure in melt-spun $\mathrm{Mg}-\mathrm{Pd}$ alloys, $\bigcirc$ : amorphous; $\mathbf{0}$ : crystalline.

$\mathrm{Mg}_{92} \mathrm{Pd}_{8}$ alloy.

Figure 4 shows DSC curves of the amorphous $\mathrm{Mg}_{100-x} \mathrm{Pd}_{x}$ $(x=10,20$ and 30 at $\%)$ alloys. No supercooled liquid region is observed before crystallization. The crystallization temperature, $T_{\mathrm{x}}$ increases with increasing Pd content, indicating that the thermal stability of the amorphous phase is improved with $\mathrm{Pd}$ content. It is also seen that the number of crystallization peaks decreases with increasing Pd content. The crystallization process changes into a more simple mode for the higher Pd content alloys.

Crystalline phases appeared in the $\operatorname{Mg}_{100-x} \operatorname{Pd}_{x}(x=10,20$ and 30 at\%) amorphous alloys after heat treatment were identified by XRD observation. The samples annealed for $1 \mathrm{~h}$ at the temperature just below the first crystallization peak in evacuated quartz tubes were used to know the first-stage crystallization behavior of the $\mathrm{Mg}_{90} \mathrm{Pd}_{10}$ and the $\mathrm{Mg}_{80} \mathrm{Pd}_{20}$ amorphous alloys. Heat treatment was also performed by using the DSC equipment to know the crystallization behavior for second and third exothermic peaks. The samples were cooled rapidly soon after recognizing the appearance of the crystallization peak in the DSC curve at which we would like to identify the crystallization process. Figure 5 shows the XRD patterns of the $\mathrm{Mg}_{90} \mathrm{Pd}_{10}$ amorphous alloy after heat treatments. The first-stage crystallization was examined by heating the sample at $400 \mathrm{~K}$ for $1 \mathrm{~h}$. It is seen that the first exothermic peak is due to the precipitation of $\mathrm{Mg}$ phase and the second peak comes from the precipitation of $\mathrm{Mg}_{6} \mathrm{Pd}$ phase from the remaining amorphous phase. The third peak appears to correspond to the transition to $\mathrm{Mg}+\mathrm{Mg}_{6} \mathrm{Pd}+$ unknown phases.

Figure 6 shows the XRD patterns of the $\mathrm{Mg}_{80} \mathrm{Pd}_{20}$ amorphous alloy subjected to the heat treatments corresponding to the two exothermic peaks. The first-stage crystallization was examined by heating the sample at $473 \mathrm{~K}$ for $1 \mathrm{~h}$. The crystallization occurs through $\mathrm{Am} \rightarrow$ $\mathrm{Am}+$ unknown phase $\rightarrow$ unknown $+\mathrm{Mg}_{6} \mathrm{Pd}$ and $\mathrm{Mg}_{5} \mathrm{Pd}_{2}$. Although the unknown phase at the first crystallization peak is predicted as $\mathrm{Mg}_{4} \mathrm{Pd}$ or $\mathrm{Mg}_{3} \mathrm{Pd}$ phase on the basis of the $\mathrm{Mg}-\mathrm{Pd}$ equilibrium phase diagram, no X-ray diffraction data of their phases are observed.

Figure 7 shows the XRD pattern of the $\mathrm{Mg}_{70} \mathrm{Pd}_{30}$ amorphous alloy heated up to $570 \mathrm{~K}$ in the DSC equipment. Both $\mathrm{Mg}_{5} \mathrm{Pd}_{2}$ and unknown phases are observed. The unknown phase cannot be identified as $\mathrm{Mg}_{3} \mathrm{Pd}$ or $\mathrm{MgPd}$ which is predicted from the $\mathrm{Mg}-\mathrm{Pd}$ equilibrium phase diagram.

Table 1 summarizes crystallization temperature, $T_{\mathrm{x}}$, tensile strength, $\sigma_{\mathrm{f}}$ and Vickers hardness, $H v$ of melt-spun amorphous $\operatorname{Mg}_{100-x} \operatorname{Pd}_{x}(x=10,20$ and 30 at\%) alloys. There is a tendency for $T_{\mathrm{x}}, \sigma_{\mathrm{f}}$ and $H v$ to increase with increasing $\mathrm{Pd}$ 

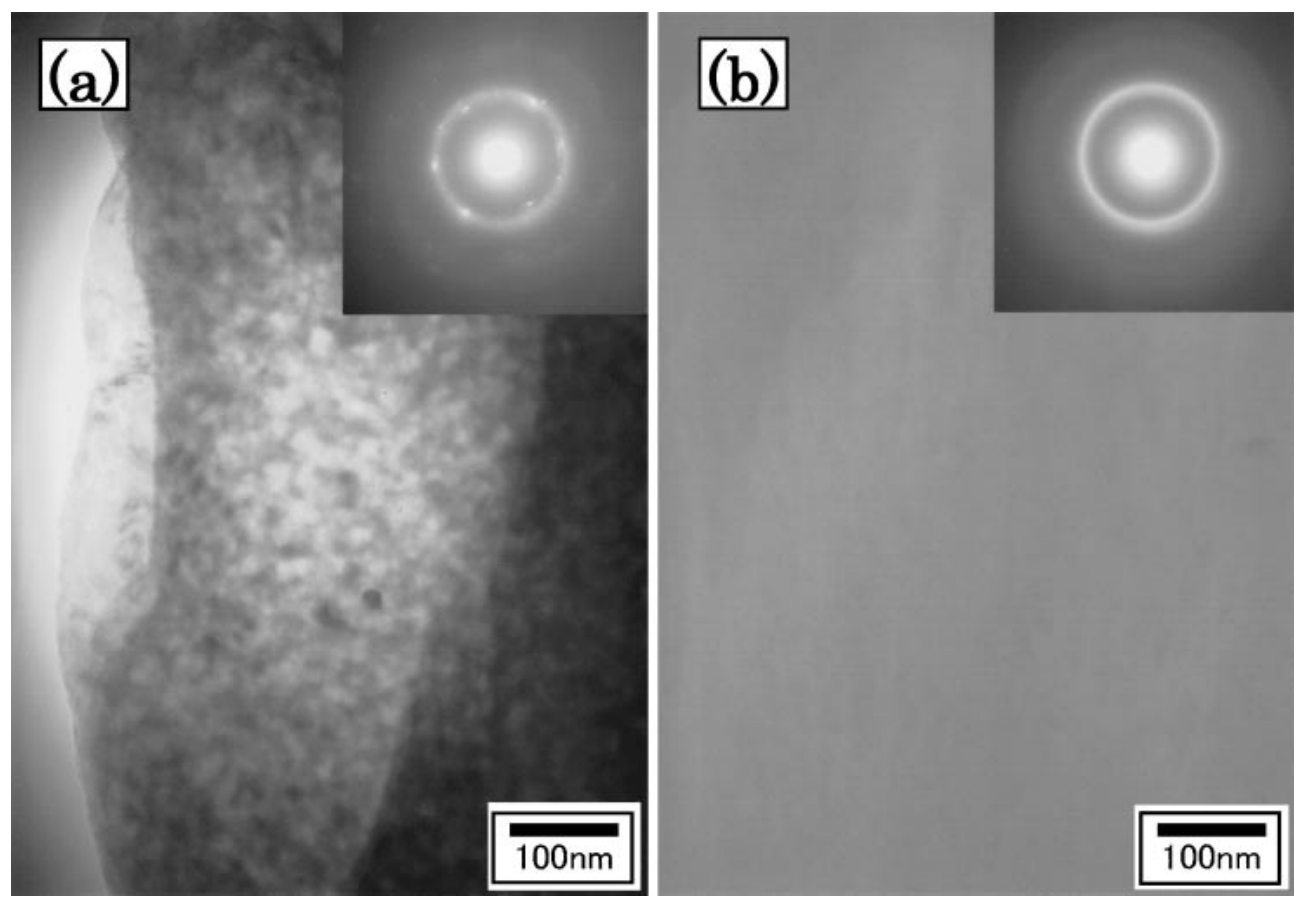

Fig. 3 TEM bright-field images and diffraction rings of melt-spun (a) $\mathrm{Mg}_{92} \mathrm{Pd}_{8}$ and (b) $\mathrm{Mg}_{90} \mathrm{Pd}_{10}$ alloys.

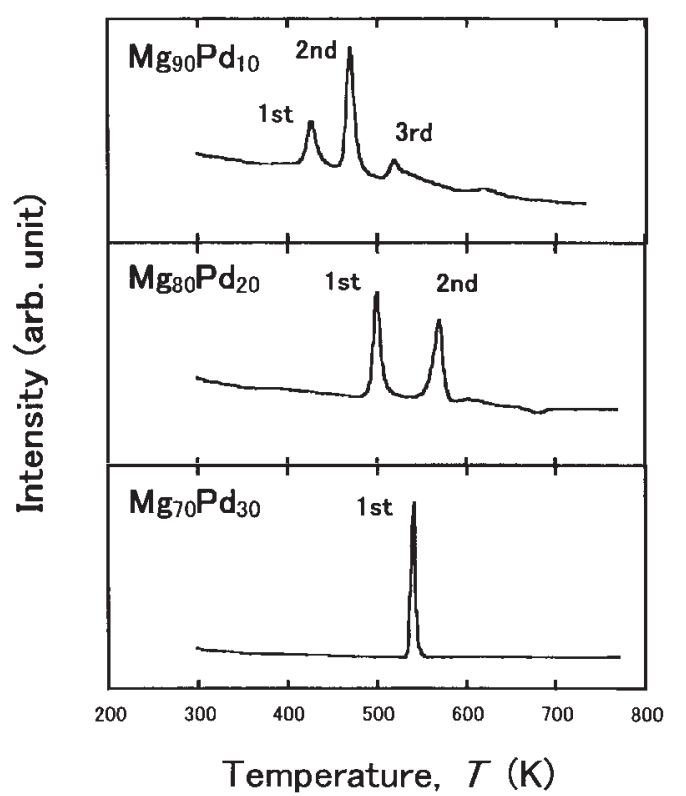

Fig. 4 DSC curves of melt-spun $\operatorname{Mg}_{100-x} \operatorname{Pd}_{x}(x=10,20$ and 30 at $\%)$ alloys.

content. The $\mathrm{Mg}_{60} \mathrm{Pd}_{40}$ crystalline alloys are too brittle to measure the tensile fracture strength.

Inoue et al. reported that the composition range of $\mathrm{Mg}-\mathrm{Ni}$ binary amorphous alloys was limited to $8<\mathrm{Ni}<25$ at $\% \mathrm{Ni}^{6}$. It is known that the feature of the $\mathrm{Mg}-\mathrm{Pd}$ equilibrium phase diagram is similar to that of the $\mathrm{Mg}-\mathrm{Ni}$ phase diagram because Pd belongs to the same group number as that of $\mathrm{Ni}$. In this work, it was shown that the composition range of the $\mathrm{Mg}-\mathrm{Pd}$ binary amorphous alloys was limited to $10<\mathrm{Pd}<$ 35 at\%Pd. Thus, the composition range of the $\mathrm{Mg}-\mathrm{Pd}$ amorphous alloys is slightly wider than that for the $\mathrm{Mg}-\mathrm{Ni}$ amorphous alloys. The mixing enthalpies of $\mathrm{Mg}-\mathrm{Pd}$ and $\mathrm{Mg}-$

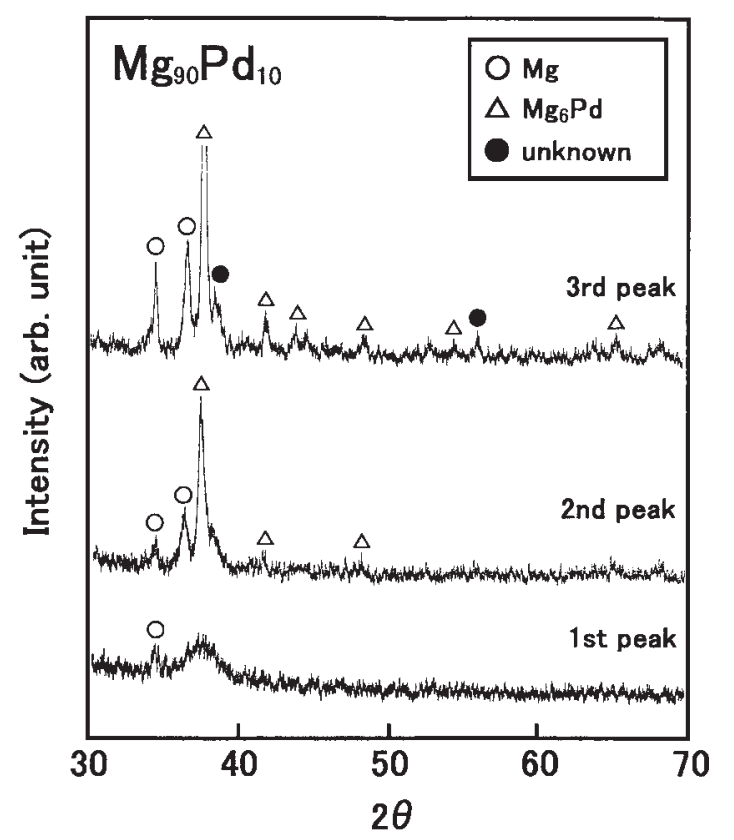

Fig. 5 Identification of precipitated crystalline phases appeared at the three distinct crystallization exothermic peaks.

$\mathrm{Ni}$ pairs are $-40 \mathrm{~kJ} /($ mole of atoms) and $-4 \mathrm{~kJ} /$ (mole of atoms), respectively. ${ }^{13)}$ These data suggest that the amorphous phase is produced more easily in the $\mathrm{Mg}-\mathrm{Pd}$ system having the larger negative mixing enthalpy than in the $\mathrm{Mg}-$ Ni system.

\section{Conclusions}

We examined the structure, thermal stability and mechanical properties of the melt-spun $\mathrm{Mg}-\mathrm{Pd}$ binary alloys. The results obtained are summarized as follows. 


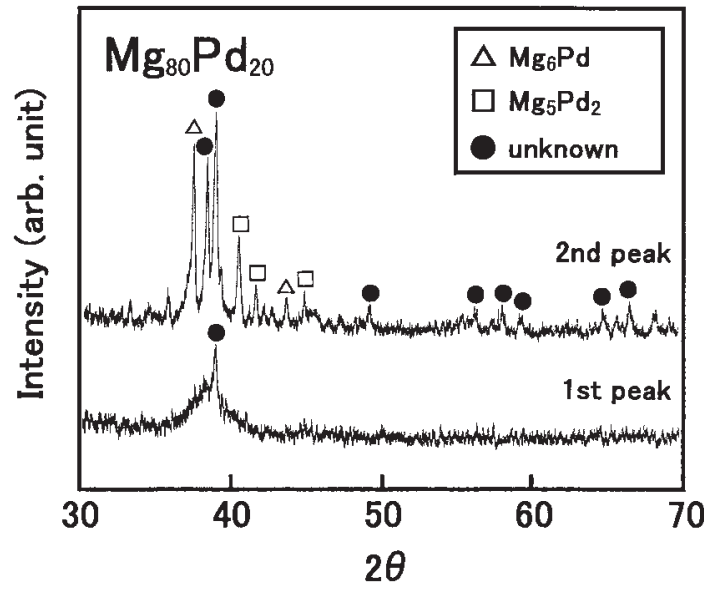

Fig. 6 Identification of precipitated crystallization phases appeared at the two distinct crystallization exothermic peaks.

Table 1 Summary of crystallization temperature, $T_{\mathrm{x}}$, tensile strength, $\sigma_{\mathrm{f}}$ and Vickers hardness, $H v$ of melt-spun amorphous $\operatorname{Mg}_{100-x} \operatorname{Pd}_{x}(x=10$, 20 and 30 at\%) binary alloys.

\begin{tabular}{cccc}
\hline Pd content $(\mathrm{at} \%)$ & $T_{\mathrm{x}}(\mathrm{K})$ & $\sigma_{\mathrm{f}}(\mathrm{MPa})$ & $H v$ \\
\hline 10 & 417 & 440 & 200 \\
20 & 492 & 630 & 315 \\
30 & 535 & 650 & 354 \\
\hline
\end{tabular}

(1) Amorphous alloys in the $\mathrm{Mg}-\mathrm{Pd}$ system were formed in a composition range of 10 to 35 at $\% \mathrm{Pd}$.

(2) Crystallization of the amorphous phase takes place through three-stage reactions of $\mathrm{Am} \rightarrow \mathrm{Am}+\mathrm{Mg} \rightarrow \mathrm{Am}+$ $\mathrm{Mg}+\mathrm{Mg}_{6} \mathrm{Pd} \rightarrow \mathrm{Mg}+\mathrm{Mg}_{6} \mathrm{Pd}+$ unknown for the $\mathrm{Mg}_{90} \mathrm{Pd}_{10}$ alloy, two-stage reactions of $\mathrm{Am} \rightarrow \mathrm{Am}+$ unknown $\rightarrow$ $\mathrm{Mg}_{5} \mathrm{Pd}_{2}+\mathrm{Mg}_{6} \mathrm{Pd}+$ unknown for the $\mathrm{Mg}_{80} \mathrm{Pd}_{20}$ alloy and single-stage reaction of $\mathrm{Am} \rightarrow \mathrm{Mg}_{5} \mathrm{Pd}_{2}+$ unknown for the $\mathrm{Mg}_{70} \mathrm{Pd}_{30}$ alloy.

(3) The $T_{\mathrm{x}}, \sigma_{\mathrm{f}}$ and $H v$ of the amorphous $\mathrm{Mg}_{100-x} \mathrm{Pd}_{x}(x=10$, 20 and 30 at\%) alloys are in the range from 417 to $535 \mathrm{~K}, 440$ to $650 \mathrm{MPa}$ and 200 to 354 , respectively. There is a tendency

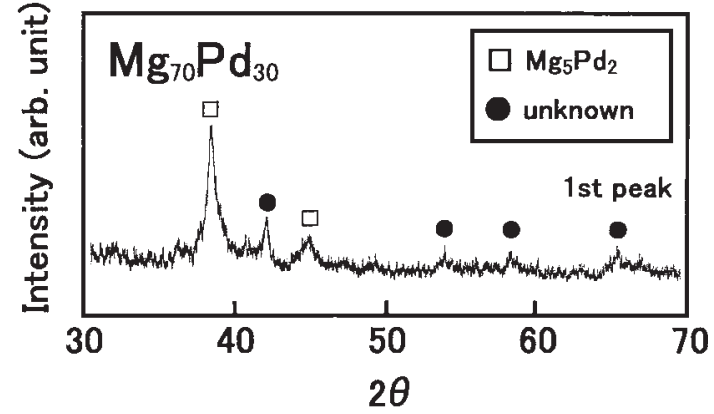

Fig. 7 Identification of precipitated crystallization phases appeared at a distinct crystallization exothermic peak.

for $T_{\mathrm{x}}, \sigma_{\mathrm{f}}$ and $H v$ to increase with increasing $\mathrm{Pd}$ content. The tendency is due to an increase in the number of $\mathrm{Mg}-\mathrm{Pd}$ atomic pairs with large negative mixing enthalpy.

\section{REFERENCES}

1) A. Inoue, K. Ohtera, K. Kita and T. Masumoto: Jpn. J. Appl. Phys. 27 (1988) L2248-L2251.

2) J. J. Reilly and R. H. Wishall: J. Inorg. Chem. 7 (1968) 2254-2256.

3) A. Inoue: Mater. Trans., JIM 36 (1995) 866-875.

4) A. Suganuma, T. Kato, H. Horikiri, Y. Kawamura, A. Inoue and T. Masumoto: Cryst. Res. Technol. 1 (1993) 112-117.

5) M. Matsuura, T. Fukunaga and U. Mizutani: Cryst. Res. Technol. 1 (1993) 464-468.

6) A. Inoue, M. Kohinata, A. P. Tsai and T. Masumoto: Mater. Trans., JIM 30 (1989) 378-381.

7) S. Orimo, A. Zuettel, K. Ikeda, S. Saruki, T. Fukunaga, H. Fujii and L. Schlapbach: J. Alloy. Compd. 293-295 (1999) 437-442.

8) S. Nohara, N. Fujita, S. G. Zhang, H. Inoue and C. Iwakura: J. Alloy. Compd. 267 (1998) 76-78.

9) S. Yamaura, H. Y. Kim, H. M. Kimura, A. Inoue and Y. Arata: J. Alloy. Comp. 347 (2002) 239-243.

10) in Pearson's Handbook of Crystallographic Data for Intermetallic Phases -2nd Edition-, Eds., P. Villars and L. D. Calvert, (ASM International, 1991).

11) R. Ferro: J. Less-Common Met. 1 (1959) 424-438.

12) A. A. Nayeb-Hashemi and J. B. Clark: Bull. Alloy Phase Diagrams 6 (1985) 164-167.

13) in COHESION IN METALS -TRANSITION METAL ALLOYS-, Eds., F. R. de Boer et al., (Elsevier Science Publishers B.V., 1988). 